\title{
Bio-efficacy of biopesticides and certain chemical insecticides against mustard aphid (Lipaphis erysimi Kalt.) on mustard crop under field condition
}

\author{
SACHIN KUMAR* AND ASHWANI KUMAR
}

Department of Entomology, Sam Higginbottom Institute of Agriculture, Technology and Sciences, ALLAHABAD (U.P.) INDIA

\section{ARITCLE INFO}

Received : 25.01 .2015

Revised : 14.02 .2016

Accepted : 28.02.2016

KEY WORDS :

Aphid, Biopesticides, Dimethoate, Lipaphis erysimi Kalt., Malathion, Neem oil

*Corresponding author:

Email: sachin.entomology@gmail.com

\begin{abstract}
The experiment was conducted on bio-efficacy of Biopesticides and certain chemical insecticides against mustard aphid (Lipaphis erysimi Kalt.) at research farm Department of Entomology, SHIATS Allahabad during Rabi season of 2012-2013. Bio-efficacy of Biopesticides and certain chemical insecticides against mustard aphid (Lipaphis erysimi Kalt.) on mustard revealed that treatments of Dimethoate $30 \mathrm{EC}$ followed by spraying of Malathion $50 \mathrm{EC}$ and Neem oil $(0.5 \%)$ were found more effective for control of Lipaphis erysimi Kalt., respectively. Whereas, the descending order of treatments were Neem oil $>$ NSKE $>$ Tobacco Leaf extract $>$ Bacillus thuringiensis $>$ Beauveria bassiana > Metarhizium anisopliae. The least effective treatment was Verticillium lecanii. Maximum infestation was recorded in control.
\end{abstract}

How to view point the article : Kumar, Sachin and Kumar, Ashwani (2016). Bio-efficacy of biopesticides and certain chemical insecticides against mustard aphid (Lipaphis erysimi Kalt.) on mustard crop under field condition. Internat. J. Plant Protec., 9(1) : 129-132. 